\title{
Modelling of Price Demand Elasticity for Entry to Bus Terminals
}

\author{
M. Lánská* \\ Faculty of Transportation Sciences, Czech Technical University in Prague, Czech Republic \\ *Corresponding author: lanska@fd.cvut.cz \\ DOI: $10.2478 / \mathrm{v} 10158-010-0008-\mathrm{y}$
}

ABSTRACT: This article deals with the modelling of price demand elasticity for entry to bus terminals. The model was applied to a specific bus terminal - CBT Prague Florenc (the abbreviation CBT stands for Central bus terminal).

KEY WORDS: Demand elasticity, price demand elasticity coefficient, linear regressive model, distant and influential observation, bus terminal.

\section{INTRODUCTION}

Demand elasticity represents an important mix of information that can be used by a company's management to aim their marketing efforts when acquiring new customers, i.e., bus carriers, and gathering information about corresponding customer/potential customer reactions to their price offers. Changes in pricing can be used to determine additional bus carriers or revenues that can be achieved by changing price policy. From the demand and elasticity theory results that calculating and estimating reactions in demand for entering bus terminal based on changes in pricing can be used both a relative coefficient price elasticity $e_{x, y}$ calculus in each observed demand values and corresponding fees for arrival charges, or calculating coefficients of price elasticity $e_{P}$ with the help of linear model.

\section{PRICE ELASTICITY OF DEMAND IN ENTERING BUS TERMINAL MODELLING}

Price elasticity of demand in entering bus terminal has been applied to an example of CBT Prague Florenc bus terminal.

2.1 Calculating coefficients of price elasticity of demand in entering bus terminal CBT Prague Florenc

The price elasticity effect represents a corresponding reaction of the bus carrier on changes in arrival fees by the bus terminal CBT Prague Florenc operator ČSAD Prague holding corp. (ČSAD is the national bus carrier.)

The indicator of this change is the coefficient of price elasticity $e_{P}$ that can be expressed by a formula:

$$
e_{P}=\frac{y_{1}-y_{0}}{\left(y_{1}+y_{0}\right) / 2}: \frac{x_{1}-x_{0}}{\left(x_{1}+x_{0}\right) / 2}
$$

Where $y_{1}$ is demand at the new price, $y_{0}$ is demand at the current price, $x_{1}$ is the new price and $x_{0}$ is the current price. 
The coefficient of price elasticity can be expressed as a fraction of the percentage change in the amount of demand and the percentage changes of prices. According to the values that $e_{P}$ can gain we can determine demand dependence on price:

1. Elastic, when $e_{P}<1$, i.e., a decline in the arrival fee of $1 \%$ causes a demand rise of more than $1 \%$, assuming constant incomes of bus carriers and constant arrival fee of other bus terminal operators, revenues of bus terminal operators rise, amount of outlays by bus carriers declines, fee-demand function is declining and has got a negative order.

2. Unit elastic, when $e_{P}=1$, i.e., the demand percentage change equals the fee percentage change with the opposite sign, revenues of bus terminal operators do not change as well as the outlays of bus carriers assuming constant incomes of bus carriers and constant arrival fees of other bus terminal operators, the function can be graphically shown as a hyperbola, the order of the price demand function equals zero.

3. Inelastic when $e_{P}>1$, i.e., the demand percentage change is lower than the fee percentage change, the drop in the arrival fee invokes a drop in the terminal operator's revenues assuming constant incomes of bus carriers and constant arrival fees of other bus terminal operators, rise in outlays of bus carriers, order of the price demand function is positive.

Because the amount of demand goes in the opposite direction than the fee rise (a rise in fees leads to a decline in demand and also the other way round), the price elasticity demand is negative.

Statistical data for calculating price elasticity is partly data from CBT Prague Florenc bus terminal operator ČSAD Prague holding corp. and partly expert estimates. Arrival fee development at CBT Prague Florenc bus terminal from the years 2002 to 2006 is stated in table 1 . We used a weighted average to calculate the average arrival fee. Weights for different bus lines are stated in table 2, since 2006 all bus lines originating in Slovakia have been a part of international bus lines. Because of the low amount of data and the small differences between arrival fees in given years it was not possible to carry out a linear regression and coefficient calculation for each bus line operating at the bus terminal CBT Prague Florenc, i.e., international lines, domestic lines, and lines originating in Slovakia, however, the average arrival fees have been calculated for each year. Price elasticity coefficients in table 3 have been calculated accordingly to the $e_{P}$ formula.

Table 1: CBT Prague Florenc - Arrival fees.

\begin{tabular}{|l|l|l|l|l|l|}
\hline Year & 2002 & 2003 & 2004 & 2005 & 2006 \\
\hline Arrival fees [CZK]: & 250 & 250 & 260 & 260 & 275 \\
\hline Domestic lines & 600 & 620 & 630 & 630 & 650 \\
\hline International lines & 480 & 500 & 540 & 540 & 0 \\
\hline Slovakia lines & 360.50 & 366.30 & 362.90 & 362 & 368.75 \\
\hline Average price (weighted average) &
\end{tabular}

Table 2: CBT Prague Florenc - Weights

\begin{tabular}{|l|l|l|l|l|l|}
\hline Year & 2002 & 2003 & 2004 & 2005 & 2006 \\
\hline Weights for: \\
\hline Domestic lines & $65 \%$ & $65 \%$ & $70 \%$ & $70 \%$ & $75 \%$ \\
\hline International lines & $25 \%$ & $24 \%$ & $21 \%$ & $20 \%$ & $25 \%$ \\
\hline Slovakia lines & $10 \%$ & $11 \%$ & $9 \%$ & $10 \%$ & - \\
\hline
\end{tabular}


Table 3: CBT Prague Florenc - Price elasticity coefficients

\begin{tabular}{|l|l|l|l|l|l|}
\hline Year & 2002 & 2003 & 2004 & 2005 & 2006 \\
\hline Total number of check out buses & 194000 & 227000 & 228000 & 230000 & 220000 \\
\hline Average price of arrival feel [CZK] & 360.50 & 366.50 & 362.90 & 360.00 & 365.75 \\
\hline Price elasticity coefficients & - & 9.82 & -0.47 & -3.25 & -2.41 \\
\hline
\end{tabular}

\section{LINEAR REGRESSION - RESULTS}

\subsection{Example 1 - with distant and influential observation}

Linear regression was at first carried out for the years from 2002 through 2006, i.e., for $n=5$ including distant and influential observation - year 2002. Regression results have proved that this point must be excluded from the data file. The final linear model formula determined by regression analyses using Microsoft Excel achieved the following form:

$$
Y=-410634.2+1731.5 . X
$$

The final formula cannot be considered to be a linear model describing the relation between the total number of processed buses and the average arrival fee price at CBT Prague Florenc bus terminal. The data reliability is $46 \%$ and therefore we cannot state the statistically important relation between the number of processed buses and the arrival fee price. The inefficiency of this model is also confirmed by the correlation coefficient value $r=0.3907903$ that hints at the model's weak dependence between variables. The determination coefficient is $r^{2}=0.152717$, and this is a descriptive convenience measure to use a regressive formula for predicting. The determination coefficient can have a value between 0 and 1, a value close to 0 hints that the regression formula is not suitable for predicting. The normal error of estimation is 15843.66. The results of our testing show the inapplicableness of the regression linear model in this case.

3.2 Example 2 - without distant and influential observation - Model to support price measure decision making

Linear regression has been carried out for the years 2003 to 2006, i.e., $\mathrm{n}=4$. The final linear model formula determined by regression analyses using Microsoft Excel achieved the following form:

$$
Y=694188.7-1282.1 . X
$$

The final formula can be considered to be a linear model describing the relation between the total number of processed buses and the average arrival fee price at CBT Prague Florenc bus terminal. The estimated reliability is $92 \%$. On a significance level 0.05 we have accepted the zero hypothesis $\mathrm{H}_{0}\left(\mathrm{H}_{0}\right.$ : there is not a dependence between the arrival fee price and the number of processed buses, the alternative hypothesis is $\mathrm{H}_{\mathrm{A}}$ : there is a dependence between the arrival fee price and the number of processed buses) but we reject the zero hypothesis on the significance level 0.1 . This regression example is an extreme one, however, since at a significance level of 0.08 we may or may not accept the zero hypothesis. Statistically, a hypothesis up to $10 \%$ is acceptable, but unreliable, i.e., we cannot exclude the dependence between variables. Dependency between variables is confirmed on a significant level of 5\%. If we accept the zero hypothesis then there is no dependence between the arrival fee price and the number of processed buses, which would express the position of CBT Prague Florenc bus terminal operator ČSAD Prague holding corp., 
which determines prices and has a monopoly on the bus terminal operator market in Prague. Bus carriers that want to enter Prague city center have no other choice but use CBT Prague Florenc bus terminal. If we decline $\mathrm{H}_{0}$ then there is a dependence between variables and there will be a statistically significant relation between the arrival fee price and the number of processed buses. The correlation coefficient value $\mathrm{r}=-0.919043$ hints at a strong dependence of the model between variables. The determination coefficient $r^{2}=0.84464$ is a value close to 1 , and therefore the regression formula is usable for predicting. The normal error of estimation is 2099.60. The relative elastic model coefficient $e_{x, y}$ can be determined after forming the formula:

$$
e_{x, y}=\hat{b} \cdot \frac{\bar{x}}{\bar{y}}
$$

Where $\bar{x}, \bar{y}$ are the average values $\hat{b}$.

$$
e_{x, y}=-1282,1 \cdot \frac{\bar{x}}{\bar{y}}=-2,07
$$

Remark: Relative elasticity coefficient value is defined as a relative demand change caused by a relative factor change taking effect on demand.

As the value of the relative elasticity coefficient equals -2.07 and as this value is therefore lower than -1 , this demand is elastic. This means that if there is a change in the arrival fee of $1 \%$, the demand of bus carriers changes by $2 \%$ on average.

\section{CONCLUSION}

The second example of demand price elasticity concerning arrivals at CBT Prague Florenc can be labelled as a "Model supporting decision making in fee pricing" and the bus terminal operator can accordingly determine the reaction of bus carriers on changes in arrival fees. It can be said that if bus terminal operator increase the arrival fee by $10 \%$, demand declines by $20 \%$ on average. However, revenues of the bus operator can remain the same or can even rise; this has to be calculated ad hoc by the terminal operator. That said, terminal operators can, with the price rise, also focus on a wider portfolio of services for bus carriers, improve the quality of the provided services, and offer longer terminal time slots that would help them retain or increase current revenues.

\section{ACKNOWLEDGEMENT}

This article originated under research plan Development of methods of design and operation of transport networks from the point of view of their optimization MSM6840770/43.

\section{REFERENCES}

Lánská, M.: 2007. Model of bus terminal financing. Dissertation thesis. CTU in Prague, Faculty of Transportation Sciences.

Melichar, V.: 2002. Price demand elasticity in public passenger transportation. Inaugural speech by appointment to professor. University of Pardubice, Jan Perner Transport Faculty. 